\title{
Antimicrobial activity screening of rhizosphere soil bacteria from tomato and genome-based analysis of their antimicrobial biosynthetic potential
}

\author{
Lu Zhou', Chunxu Song ${ }^{1,2}$, Zhibo Li $i^{1}$ and Oscar P. Kuipers ${ }^{1 *}$ (D)
}

\begin{abstract}
Background: Tomato plant growth is frequently hampered by a high susceptibility to pests and diseases. Traditional chemical control causes a serious impact on both the environment and human health. Therefore, seeking environment-friendly and cost-effective green methods in agricultural production becomes crucial nowadays. Plant Growth Promoting Rhizobacteria (PGPR) can promote plant growth through biological activity. Their use is considered to be a promising sustainable approach for crop growth. Moreover, a vast number of biosynthetic gene clusters (BGCs) for secondary metabolite production are being revealed in PGPR, which helps to find potential anti-microbial activities for tomato disease control.

Results: We isolated 181 Bacillus-like strains from healthy tomato, rhizosphere soil, and tomato tissues. In vitro antagonistic assays revealed that 34 Bacillus strains have antimicrobial activity against Erwinia carotovora, Pseudomonas syringae; Rhizoctonia solani; Botrytis cinerea; Verticillium dahliae and Phytophthora infestans. The genomes of 10 Bacillus and Paenibacillus strains with good antagonistic activity were sequenced. Via genome mining approaches, we identified 120 BGCs encoding NRPs, PKs-NRPs, PKs, terpenes and bacteriocins, including known compounds such as fengycin, surfactin, bacillibactin, subtilin, etc. In addition, several novel BGCs were identified. We discovered that the NRPs and PKs-NRPs BGCs in Bacillus species are encoding highly conserved known compounds as well as various novel variants.
\end{abstract}

Conclusions: This study highlights the great number of varieties of BGCs in Bacillus strains. These findings pave the road for future usage of Bacillus strains as biocontrol agents for tomato disease control and are a resource arsenal for novel antimicrobial discovery.

Keywords: Bacillus, Plant growth promoting Rhizobacteria (PGPR), Genome mining, Tomato, Rhizosphere, Biosynthetic gene clusters, Non-ribosomal synthesized peptides, Polyketides, Bacteriocins

\footnotetext{
* Correspondence: o.p.kuipers@rug.nl

'Department of Molecular Genetics, University of Groningen, Groningen, The Netherlands

Full list of author information is available at the end of the article
}

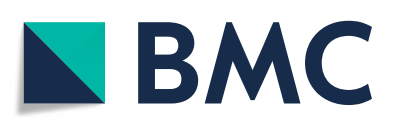

(c) The Author(s). 2021 Open Access This article is licensed under a Creative Commons Attribution 4.0 International License, which permits use, sharing, adaptation, distribution and reproduction in any medium or format, as long as you give appropriate credit to the original author(s) and the source, provide a link to the Creative Commons licence, and indicate if changes were made. The images or other third party material in this article are included in the article's Creative Commons licence, unless indicated otherwise in a credit line to the material. If material is not included in the article's Creative Commons licence and your intended use is not permitted by statutory regulation or exceeds the permitted use, you will need to obtain permission directly from the copyright holder. To view a copy of this licence, visit http://creativecommons.org/licenses/by/4.0/. The Creative Commons Public Domain Dedication waiver (http://creativecommons.org/publicdomain/zero/1.0/) applies to the data made available in this article, unless otherwise stated in a credit line to the data. 


\section{Background}

Tomato (Solanum lycopersicum) is the second most important vegetable crop worldwide after potato, based on the sizes of their growth areas [1]. However, tomato crops face serious threats of disease, partially due to the use of cultivars susceptible to diseases that are causing substantial production losses [2]. The overuse of chemical pesticides has contaminated soils and has caused harmful effects on human beings [3]. Accordingly, putting biocontrol agents isolated from nature into the soil is environmentally friendly and useful for tomato crop disease control. One way to improve plant growth is by using plant growth-promoting rhizobacteria (PGPR), since PGPR have the ability to colonize the roots and express their plant growth promotion activities in the rhizosphere [4].

The rhizosphere, a narrow zone of soil that surrounds and is influenced by plant roots, gives home to an overwhelming variety of organisms, in particular microorganisms such as bacteria, fungi, oomycetes, archaea, protozoa and algae [5, 6]. This complex microbial community has profound effects on plant growth since it facilitates nutrient absorption and provides health protection to plants [7]. Among all the microorganisms, PGPR has been largely described for their biocontrol capabilities. They can promote plant growth either indirectly by suppression of diseases with secreted antimicrobials or directly by the improvement of physiological metabolic processes such as $\mathrm{N}_{2}$ fixation, phosphate solubilization and IAA production [8].

Among PGPR, the group of Gram-positive Bacillus strains has been studied less intensively, compared to widely used Gram-negative bacteria, like Pseudomonas strains [9]. One of the most efficient Gram-positive bacteria that promote plant growth belongs to the genus $\mathrm{Ba}$ cillus. Bacillus subtilis is used in agriculture to protect plants from several plant pathogens since it can either indirectly protect plants by inducing systemic resistance (ISR) against a broad range of pathogens or directly excrete antimicrobials [10-13]. Besides, Bacillus species can produce hard, resistant endospores to allow them to resist adverse environmental conditions and permit easy formulation and storage of the commercial products [14].

The Bacillus species offer a plethora of antagonistic compounds displaying a broad range of biological functions, which have good potential to be used as biocontrol agents for tomato disease control [15]. All the bioactive secondary metabolites are encoded by biosynthetic gene clusters (BGCs). Based on their products, BGCs are classified as ribosomally synthesized peptides (linear bacteriocin BGCs and ribosomally-produced an posttranslationally modified peptides [RiPPs]), nonribosomally synthesized peptides synthetases (NRPSs) BGCs and polyketide synthases (PKSs) BGCs [16]. Here, we set out to find novel BGCs in Bacillus strains which encode potentially active compounds to inhibit plantpathogens. Based on genome mining, 10 selected (out of 351) promising Bacillus strains newly isolated from rhizosphere soils of healthy tomato plants and tissues were characterized with respect to anti-pathogen activities. Subsequently, several novel BGCs were discovered, which have potential functions in tomato pathogens antagonism.

\section{Results}

Isolation of Bacteria and in vitro antagonistic assay

A total of 181 Bacillus-like strains were isolated from healthy tomato rhizosphere soil and tomato plant tissue collected in either the Netherlands or Spain. Among them, 28 endophytic strains were isolated from healthy tomato plant tissues collected in Spain. 74 and 79 rhizosphere bacteria strains were isolated from tomato plants collected in Spain and the Netherlands, respectively. In order to identify potential PGPR strains, all the Bacilluslike strains were preliminarily screened by in vitro antagonistic activity against six major tomato plant pathogens, i.e. Erwinia carotovora [17], Pseudomonas syringae [18], Rhizoctonia solani [3], Botrytis cinerea [19], Verticillium dahliae [20], and Phytophthora infestans [21]. The results revealed that 34 Bacillus-like strains could inhibit different bacterial, fungal and oomycetal plant pathogens growth on plates (Figs. 1 and 2).

We found that 34 Bacillus-like strains were distributed between three large major clusters of the neighbor-joining tree based on 16S rRNA genes. In the first cluster, strain EDO6 was clustered within the genus of Paenibacillus, which was related to type strain Paenibacillus xylanexedens B22a, with the percent identity value above $99.6 \%$ on $16 \mathrm{~S}$ rRNA gene sequence. Ten isolated strains were grouped in the second cluster and were closely related to the type strains Bacillus endophyticus 2DT and MF126, Bacillus firmus IAM 12464, Bacillus megaterium NBRC 15308, or Bacillus aryabhattai $\mathrm{B} 8 \mathrm{~W} 22$. The third cluster consisted of 23 isolated strains. They were tightly releated to reference strains Bacillus cereus ATCC 14579, Bacillus velezensis FZB42 or SQR9, Bacillus subtilis BSn5 and NCD-2.

Of all strains, seven strains (TH16, FH17, EH6, DH15, $\mathrm{BH} 4, \mathrm{BH} 5$ and $\mathrm{BH} 6$ ) showed inhibition on all pathogens. Among them, four strains (TH16, FH17, BH5 and BH6), showing the biggest inhibition halo on all pathogens, were selected to sequence their genomes for further research. In addition, three strains (EH11, EDO6 and FH5), showing the highest inhibition activity (inhibition halo size $>9.75 \mathrm{~mm}$ against $P$. infestans), were also selected for genome sequencing. Besides, two strains (EH2 and EH5), showing the highest inhibition activity (inhibition halo size $>8.5 \mathrm{~mm}$ ) against $B$. cinerea, were selected for genome sequencing as well. Strain DH12 was 


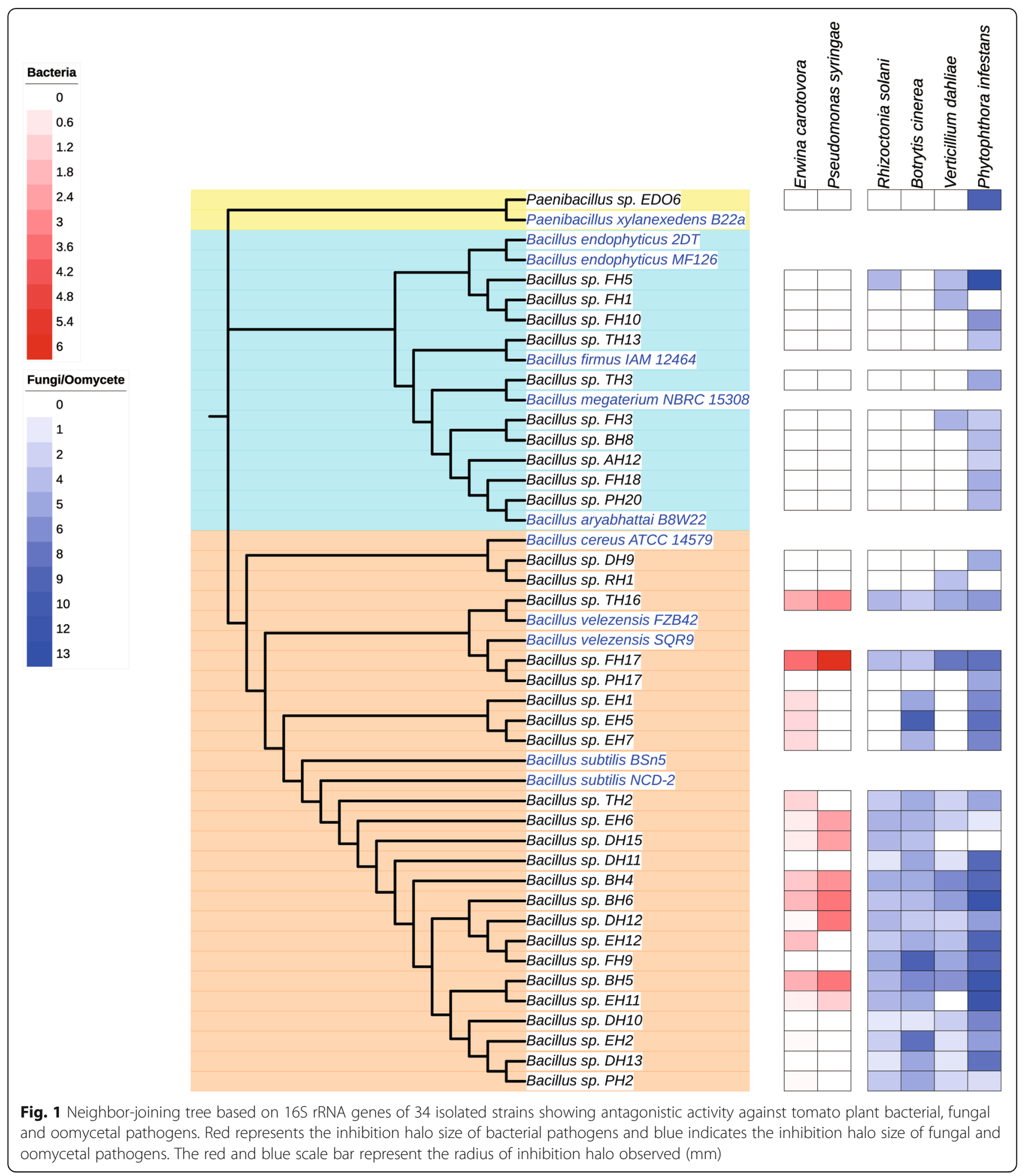

also selected for genome sequencing, because of the large inhibition halo size $(>3.38 \mathrm{~mm})$ measured on the plates against Pseudomonas syringae. In summary, a total of 10 strains (BH5, BH6, DH12, EH2, EH5, EH11, FH5, FH17, TH16 and EDO6) were genome sequenced for further research.

\section{Genome sequencing and phylogenetic analysis}

The genomes of 10 isolated strains were sequenced, assembled and annotated as described in a previous study [22]. Based on whole genome phylogenetic analyses, the 10 Bacillus strains were clustered into five clades as presented in Fig. 3. All of them were tightly clustered 


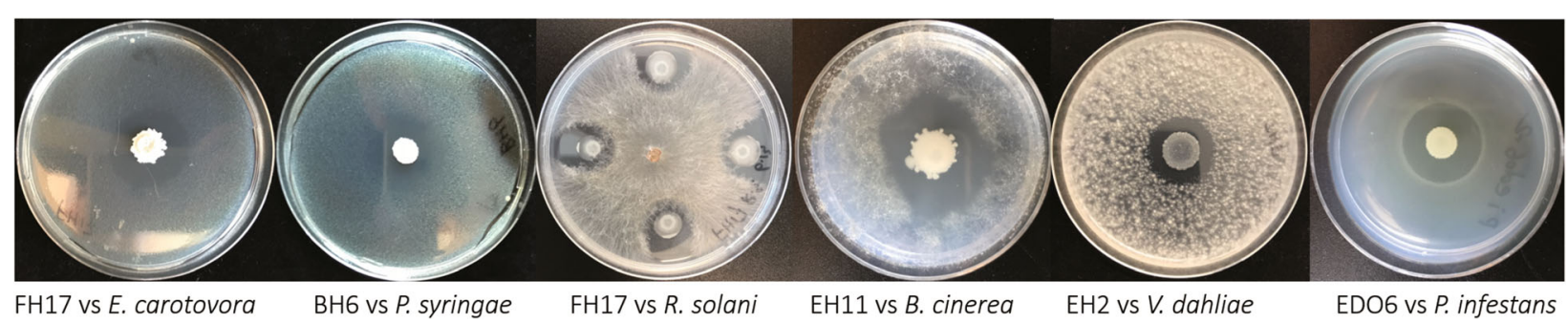

Fig. 2 Pictures of antagonistic assay for each kind of pathogens in plates

together with reported PGPR strains from the Bacillus class, such as B. subtilis Bsn5, B. velezensis FZB42 and $P$. polymyxa E681. This suggests that they probably can promote plant growth as well, which needs to be further investigated. Moreover, to classify strains at the species level, Average Nucleotide Identity (ANI) and digital DNA-DNA Hybridization (dDDH) values were determined [23] (Additional file 1: Table S1). Strains DH12, $\mathrm{EH} 2$, EH5, and EH11 were exhibiting $\geq 98.21 \% \mathrm{ANI}$ and $\geq 86.70 \% \mathrm{dDDH}$ compared with reference genome $B$. subtilis Bsn5, therefore they were identified as B. subtilis species. Strains FH17 and TH16 were identified as $B$. velezensis, based on $\geq 98.14 \%$ ANI and $\geq 85.30 \% \mathrm{dDDH}$ compared with reference genome of $B$. velezensis FZB42. Strains BH5 and BH6 were classified into B. cabrialesii species because of exhibiting 96.60\% ANI and 73.40\% $\mathrm{dDDH}$ compared with the reference genome of $B$. cabrialesii TE3. Strain FH5 was identified as B. endophyticus

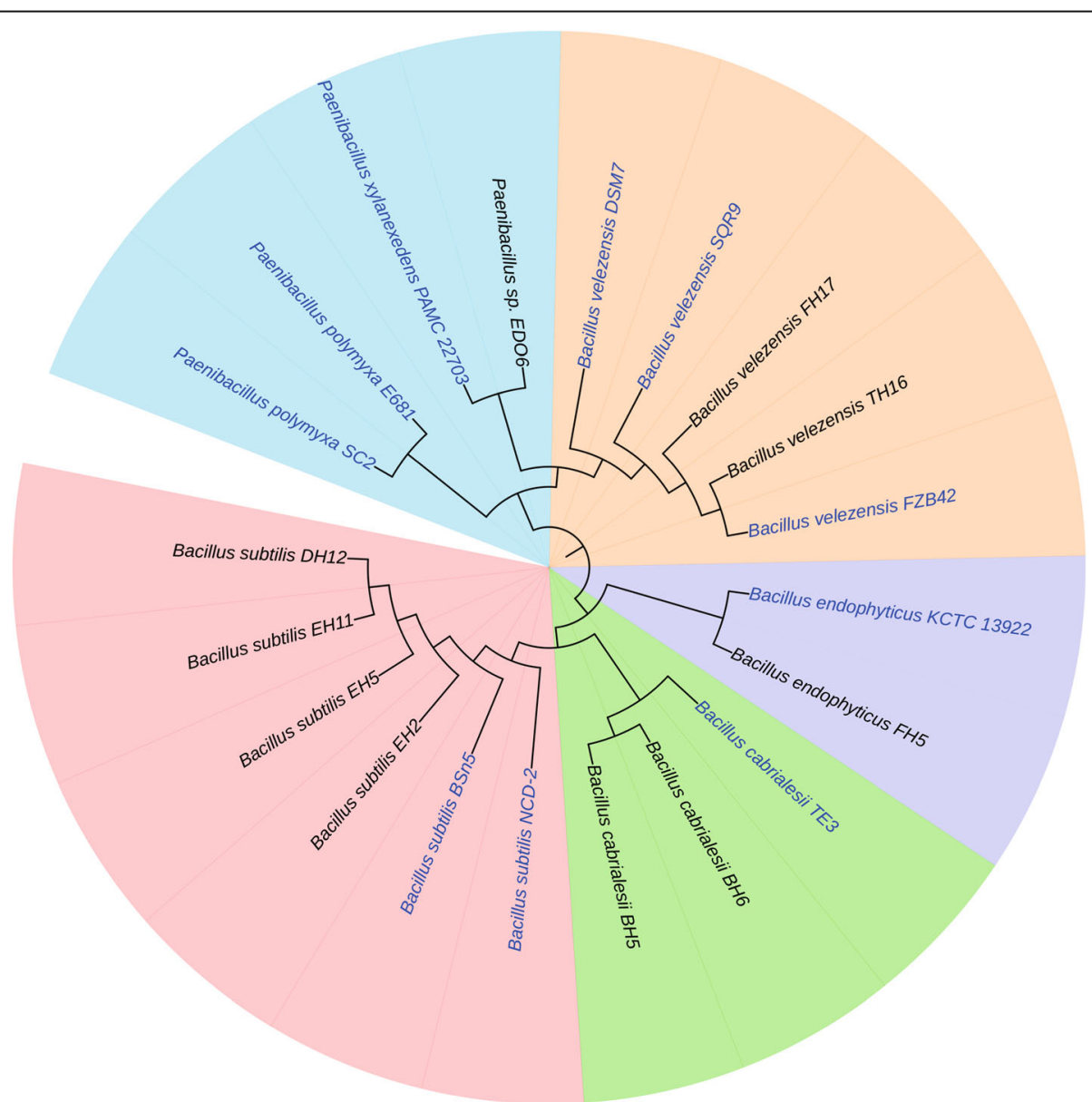

Fig. 3 Phylogenetic position of 10 isolated Bacillus and Paenibacillus strains with high significant antagonistic activity against tomato pathogens. A maximum likelihood (ML) tree was constructed based whole genome sequences analysis using Gegenee 
based on $96.35 \% \mathrm{ANI}$ and $73.40 \% \mathrm{dDDH}$ compared with reference genome B. endophyticus KCTC 13922. Strain EDO6 could not be classificated at the species level due to the low ANI and dDDH values (93.88\% ANI and $57.60 \% \mathrm{dDDH})$, even compared with the closest species P. xylanexedens PAMC 22703, so we will name it Paenibacillus sp. EDO6.

\section{Biosynthesis gene cluster (BGC) mining}

A total of 120 BGCs were found, averaging 12 clusters per genome. All the BGCs were designated as those encoding NRPSs, PKSs, terpenes, hybrid NRPS/PKSs, bacteriocins, RiPPs and others (Table 1 and Additional file 1: Table S2). The BGCs encoding surfactin [24], fengycin [24], bacillibactin [25], subtilosin A [26], bacillaene [27], macrolactin [28], difficidin [29], and subtilin [30] were discovered in the genomes. Besides, some BGCs encoding unknown compounds, were also identified (Table 1). Most of the unknown BGCs (76.47\%) are PKSs BGCs, which cannot be assigned to any known compounds. $73.07 \%$ bacteriocins BGCs encodes potential novel peptides. 27.78 and 27.27\% of NRPSs and Hybrids BGCs are still unknown. These findings provide a great opportunity of new bioactive compounds discovery.

\section{Novel NRPs and PKs BGCs identified from the 10 strains}

The majority of BGCs could be assigned to known compounds, whereas 5 clusters represented probably novel NRPs and PKs-NRPs hybrid BGCs for which no or low similarity BGCs could be identified in the MIBiG [31] database (Fig. 4).

Two novel gene clusters were identified from $B$. endophyticus FH5. One NRPs (Fig. 4a) BGC consists of three genes and has a total size of $25 \mathrm{~kb}$. Three genes are encoding 24 domains, which includes 7 condensation (C) domains, 7 adenylation (A) domian, 7 thiolation (T) domain, 2 epimerization (E) domain and 1 thioesterase (TE) domain. All the domains are essential components in this BGC and catalyze primary formation of a lipopeptide product. This BGC is showing no similarity to any known BGCs reported. The other one (Fig. 4b) is a Type I PKs-NRPs hybrid BGC with a size of approximately $30 \mathrm{~kb}$. The PKs module consists of a ketosynthase (KS) domain, a acyltransferase (AT) domain, an acyl carrier protein (ACP) domain and a terminal reductase (TD) domain. It likely incorporates the polyketide moiety of malonyl-CoA, while the NRPs modules incorporate six amino acid residues. Based on antiSMASH analysis, only $28 \%$ genes show similarity to the known paenilamicin BGC. Paenilamicin [32], synthesized by pam BGC from Paenibacillus larvae DSM25430, has antibacterial and antifungal activity. The pam cluster consists of five NRPs genes, two Type I PKs genes, and two Type I PKs-NRPs hybrid genes, and has a size of $\sim 60 \mathrm{~kb}$. In contrast, the Type I PKs-NRPs hybrid BGC identified in B. endophyticus FH5 consists of only three NRPS genes and one Type I PKS gene. All of them differ from the pam cluster of Paenibacillus larvae DSM25430.

Table 1 Distribution of BGC totals in 10 isolated strains (A) and percentages of BGCs encoded unknown compounds identified from genome sequence (B)

\begin{tabular}{|c|c|c|c|c|c|c|c|c|}
\hline \multicolumn{9}{|l|}{ A. } \\
\hline \multicolumn{2}{|l|}{ Strains } & Predicted BGCs & NRPS & PKS & Hybrid NRPS/PKS & Terpene & Bacteriocin & Other \\
\hline \multicolumn{2}{|c|}{ Bacillus cabrialesii BH5 } & 12 & 4 & 1 & 1 & 2 & 3 & 1 \\
\hline \multicolumn{2}{|c|}{ Bacillus cabrialesii BH6 } & 12 & 4 & 1 & 1 & 2 & 3 & 1 \\
\hline \multicolumn{2}{|c|}{ Bacillus subtilis DH12 } & 12 & 4 & 1 & 1 & 2 & 3 & 1 \\
\hline \multicolumn{2}{|c|}{ Bacillus subtilis EH2 } & 10 & 3 & 1 & 1 & 2 & 2 & 1 \\
\hline \multicolumn{2}{|c|}{ Bacillus subtilis EH5 } & 11 & 3 & 1 & 1 & 2 & 3 & 1 \\
\hline \multicolumn{2}{|c|}{ Bacillus subtilis EH11 } & 12 & 4 & 1 & 1 & 2 & 3 & 1 \\
\hline \multicolumn{2}{|c|}{ Bacillus endophyticus FH5 } & 10 & 2 & 1 & 1 & 2 & 3 & 1 \\
\hline \multicolumn{2}{|c|}{ Bacillus velezensis FH17 } & 15 & 5 & 4 & 1 & 2 & 1 & 2 \\
\hline \multicolumn{2}{|c|}{ Bacillus velezensis TH16 } & 12 & 4 & 4 & 1 & 1 & 1 & 1 \\
\hline \multicolumn{2}{|c|}{ Paenibacillus sp. EDO6 } & 14 & 3 & 2 & 2 & 1 & 4 & 1 \\
\hline \multicolumn{9}{|l|}{ B } \\
\hline BGC Types & Total BGCs & $\%$ Unknown & \multicolumn{6}{|c|}{ Known compounds } \\
\hline NRPSS & 36 & 27.78 & \multicolumn{6}{|c|}{ surfactin (8 BGCs), fengycin (8 BGCs), bacillibactin (10 BGCs) } \\
\hline PKSs & 17 & 76.47 & \multicolumn{6}{|c|}{ macrolactin (2 BGCs), difficidin (2 BGCs) } \\
\hline Hybrids & 11 & 27.27 & \multicolumn{6}{|c|}{ bacillaene (8 BGCs) } \\
\hline Bacteriocin & 26 & 73.07 & \multicolumn{6}{|c|}{ subtilin (2 BGCs), subtilosin A (6 BGCs) } \\
\hline
\end{tabular}



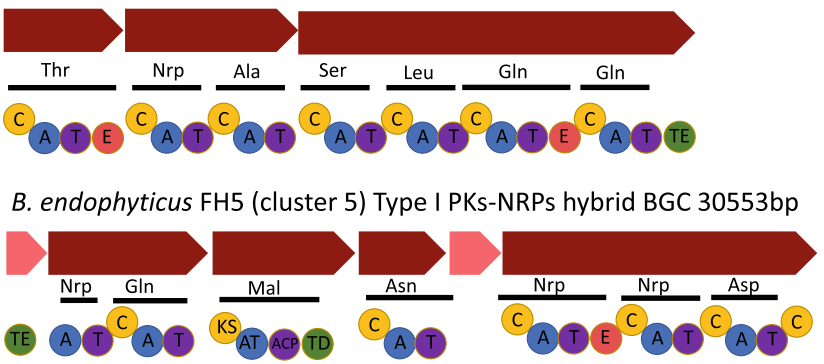

Paenibacillus sp. EDO6 (cluster 13) trans-AT PKs-NRPs hybrid BGC 35857bp

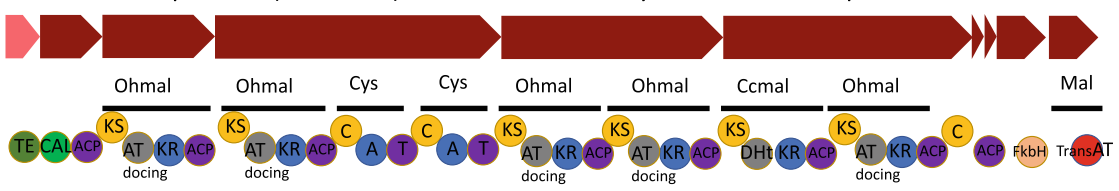

d Paenibacillus sp. EDO6 (cluster 12) trans-AT PKs-NRPs hybrid BGC 28523bp

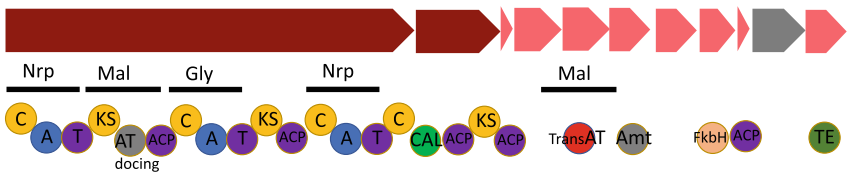

e

B. velezensis FH17 (cluster 7) TH16 (cluster 12) NRPs BGC 33403bp

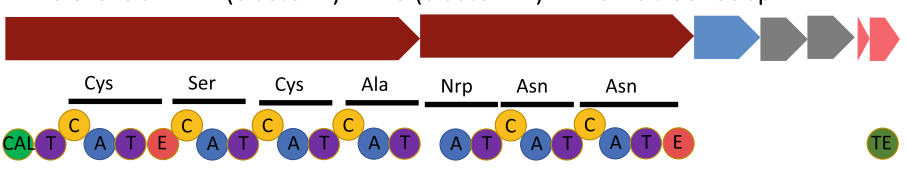
A Adenylation domain
(C) Condensation domain
Peptidyl-carrier protein domain
Epimerization domain
TH Thioesterase domain
Acyltransferase domain
KS Ketosynthase domain
Acyl-carrier protein domain
Terminal reductase domain
Amt Aminotransferase
FRb FkbH-like domain
Co-enzyme A ligase domain
AT Trans-acyltransferase docking domain

Fig. 4 Novel Biosynthetic Gene Clusters (BGCs) identified from the isolated Bacillus and Paenibacillus strains. a an NRPs BGC discovered in B. endophyticus FH5. $\mathbf{b}$ a Type I PKs-NRPs hybrid BGC found in B. endophyticus FH5. c, d two trans-AT PKs-NRPs hybrid BGCs harboered by Paenibacillus sp. EDO6. e an NRPs BGC found in both B. velezensis FH17 and TH16

In the genome of Paenibacillus sp. EDO6, two novel trans-AT PKs-NRPs hybrid gene clusters (cluster 13 and cluster 12) were discovered, which have the sizes of almost $35 \mathrm{~kb}$ and $28 \mathrm{~kb}$, respectively (Fig. $4 \mathrm{c}$ and d). The order and domain of the genes of both hybrid clusters differ from each other. Specifically, Cluster 13 has an additional dehydratase domain variant (DHt) playing an important role during polyketide biosynthesis through the dehydration of the nascent polyketide intermediate to provide olefins [33], which cannot be found in cluster 12. In addition to the differences observed at the domain level of core biosynthetic genes, regulator and transporter genes are also different. Moreover, only 33 and $21 \%$ of the genes of cluster 13 and cluster 12 exhibit similarity to known pellasoren and xenocoumacin BGCs respectively. Pellasoren [34] was isolated from myxobacterium, which has shown to possess potential anticancer activity. The known pellasoren BGC, is a Type I PKs-NRPs hybrid cluster identified from Sorangium cellulosum So ce38 and consists of six genes of Type I PKs and one single gene of NRPs as compared to the transAT PKs-NRPs hybrid gene (cluster 13) of Paenibacillus sp. EDO6, which in turn consists of four trans-AT PKs genes and one trans-AT PKs-NRPs hybrid gene. 
Xenocoumacin [35] is the main anti-bacterial and antifungal compound produced by Xenorhabdus nematophila. The known xenocoumacin BGC, also being a Type I PKs-NRPs hybrid cluster, which was identified from Xenorhabdus nematophila ATCC 19061, consists of four genes of Type I PKs and two genes of NRPs whereas cluster 12 from Paenibacillus sp. EDO6 consists of one single trans-AT domain gene, one gene of transAT PKs and one gene of trans-AT PKs-NRPs hybrid.

One novel NRPs BGC was discovered both in B. velezensis FH17 and TH16 (Fig. 4e). This BGC contains seven genes with a size of approximately $33 \mathrm{~kb}$. Whereas seven modules are only encoded by two core biosynthetic genes, seven amino acids are incorporated into the final product. This BGC shows no similarity to any known clusters. Furthermore, a single heterocyclization (Cy) domain in the first module is found.

\section{Novel Ribosomally synthesized and post-translationally modified peptides (RiPPs) identified in the 10 strains}

A total of nine novel bacteriocin BGCs were identified from the 10 strains (Fig. 5). All of them are belong to RiPPs (less than $10 \mathrm{kDa}$ ). These peptides are ribosomally synthesized, and undergo posttranslational modifications (PTMs), resulting in different structures and properties, mainly showing anti-bacterial activity against closely related producer strains [36].

Two novel gene clusters were identified as class I lanthipeptide BGCs. One lanthipeptide BGC was identified from both $B$. subtilis $\mathrm{DH} 12$ and EH11 with a size of $\sim 6 \mathrm{~kb}$ (Fig. 5a). This BGC consists of four genes. The precursor peptide contains 59 amino acids, which shows no similarity to any known bacteriocins. Another one lanthipeptide BGC (Fig. 5b) was identified from Paenibacillus sp. EDO6 with a size of $\sim 9 \mathrm{~kb}$. This BGC contains seven genes. The precursor peptide encoded by the core biosynthetic gene contains 59 amino acids, which also shows no similarity to any known bacteriocins.

Three novel BGCs were identified as class II lanthipeptide BGCs. All of them belong to two-component lanthipeptides consisting of two peptides. The individual peptides of two-component lanthipeptides only have little or no antimicrobial activity, but the two peptides act in synergy to exhibit significantly higher activity in equimolar concentrations [37]. Both B. cabrialesii $\mathrm{BH} 5$ and BH6 harbor the same two-component lanthipeptide BGC (Fig. 5c). It consists of six genes with a size of $\sim 9$ $\mathrm{kb}$. This BGC has $70 \%$ of genes showing similarity to staphylococcin C55 $\alpha / \beta$ BGC [38]. The presursors of two core biosynthetic genes ( $\alpha$ and $\beta$ ) of this BGC identified contain 65 and 67 amino acids respectively. The $C$ terminus (from C36 to K65) of the $\alpha$ precursor is belonging to the plantaricin $\mathrm{C}$ family of lantibiotics with a identity of $83.33 \%$ to the known peptide staphylococcin
$\mathrm{C} 55 \alpha$. Whereas the $\mathrm{C}$ terminus (from I38 to C67) of the $\beta$ precursor shows $62.07 \%$ identity to lacticin 3147 A2 [39]. The second novel class II lanthipeptide BGC was discovered from B. subtilis EH5 (Fig. 5d). This BGC has six genes with a length of $\sim 9 \mathrm{~kb}$. The presursors of two core peptide genes ( $\alpha$ and $\beta$ ) contain 65 and 67 amino acids respectively. It is also showing $70 \%$ gene sequence similarity to staphylococcin C55 $\alpha / \beta$ BGC. The C terminus (from C36 to C64) of the $\alpha$ precursor has a similarity of $79.31 \%$ to the known peptide staphylococcin C55 $\alpha$ and the C terminus (from W38 to C63) of the $\beta$ precursor is showing $72 \%$ identity to lacticin 3147 A2. The third BGC was identified from B. endophyticus FH5 (Fig. 5e). It is comprised of nine genes with a size of $\sim 10$ kb. Its precursors of two peptides $(\alpha$ and $\beta$ ) contain 58 and 54 amino acids respectively. There is no similarity found to any known BGCs. The $\mathrm{C}$ terminal region (from A28 to C58) of the $\alpha$ precursor has a similarity of $53.33 \%$ to the known peptide plantaricin $\mathrm{W} \alpha[40]$ and the $\mathrm{C}$ terminus (from A23 to D54) of the $\beta$ precursor is showing $56.25 \%$ identity to haloduracin $\beta$ [41]. Furthermore, the precursor $\beta$ in this potential novel BGC found in B. endophyticus FH5 has four replicates, indicating potential high amount production of $\beta$ peptide.

Two novel gene clusters were identified as class III lanthipeptide BGCs. This Class contains RiPPs that are modified by the mutifunctional enzymes LanKC. LanKC firstly phosphorylates the Ser/Thr residuses in the substrate peptide and then similarly catalytizes modification of the substrate to form the final product, as the class II lanthipeptide LanM enzyme [42]. The one identified from $B$. subtilis EH2 contains ten genes with a size of $\sim 8 \mathrm{~kb}$ (Fig. $5 \mathrm{f}$ ). No similarity was found to any known BGCs. The full precursor contains 58 amino acids. The predicted cleaveage site by antiSMASH is between T27 and G28. The C terminus (from G28 to N58) of the precursor has no identity to any known RiPPs. The other class III lanthipeptide BGC is harbored by $B$. velezensis TH16 (Fig. 5g). This one contains five genes with a length of $\sim 5 \mathrm{~kb}$. The core biosynthetic gene encodes a 45-amino acid precursor peptide. 35\% genes of this BGC show similarity to locillomycin [43], which is a cyclic lipopeptide (NRPs) discovered from B. subtilis 916. The predicted cleaveage site is between V21 and D22 by antiSMASH and the C terminus (from D22 to C45) of the precursor has no identity to any known RiPPs.

Two novel lasso peptide BGCs were identified from the genomes of Paenibacillus sp. EDO6 and B. endophyticus FH5. The one from Paenibacillus sp. EDO6 contains eight genes with a size of $\sim 8 \mathrm{~kb}$ (Fig. 5h). It shows that gene sequences are $60 \%$ similar to that of the paeninodin BGC [44]. The precursor peptide contains 45 amino acids. The predicted cleaveage site is between M22and A23. The core peptide (from A23 to S45) shows 
a B. subtilis DH12 (cluster 9) EH11 (cluster 3) Class I lanthipeptide BGC 6557bp

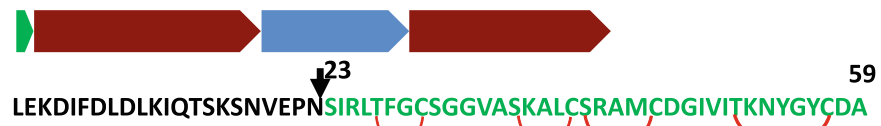

LEKDIFDLDLKIQTSKSNVEPNSIRLTFGCCSGGVASKALCSRAMCDGIVITKNYGYCCDA

b Paenibacillus sp. EDO6 (cluster 9) Class I lanthipeptide BGC 9426bp

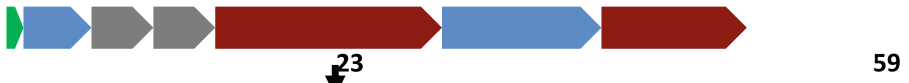

MEKGIFDLDVQIKKSEGTVQPQALSIWNCTGGCGEQTRTANTCAPTAGVKCFSNIGALC

C B. cabrialesii BH5 (cluster 8) BH6 (cluster 8) Class II lanthipeptide BGC 9464bp

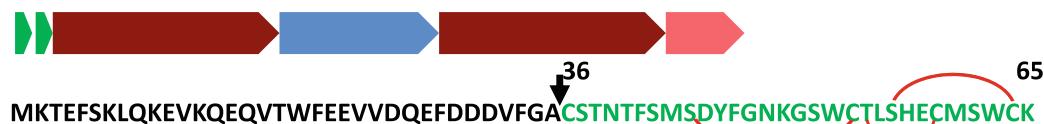

MKTEFSKLQKEVKQEQVTWFEEVVDQEFDDDVFGACSTNTFSMSPYFGNKGSWCTLSHECMSWCK MNDNKSIASNSSKKELELGKYLESDMIALTDDDVYGGITPVLSAVSGYVSGFISDNTCPTTACTRAC

d B. subtilis EH5 (cluster 1) Class II lanthipeptide BGC 9437bp

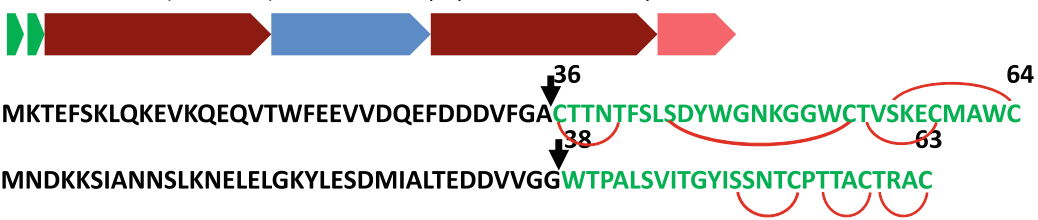

e B. endophyticus FH5 (cluster 9) Class II lanthipeptide BGC 10801bp

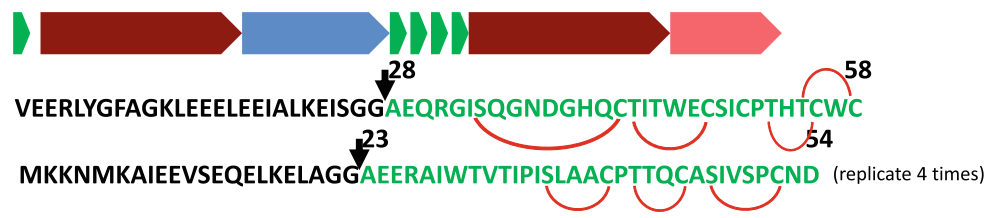

f B. subtilis EH2 (cluster 9) Class III lanthipeptide BGC 8827bp

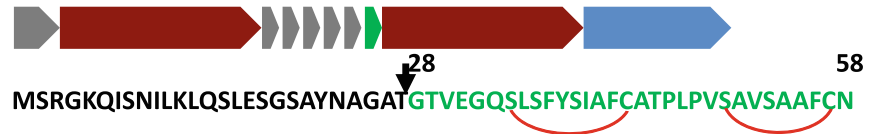

g B. velezensis TH16 (cluster 9) Class III lanthipeptide BGC 5443bp

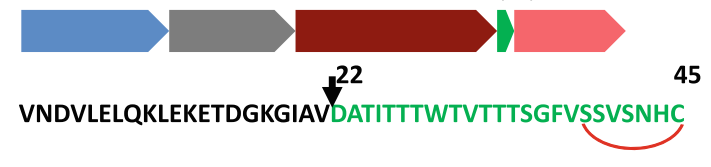

h Paenibacillus sp. EDO6 (cluster 7) Lasso peptide BGC 8236bp

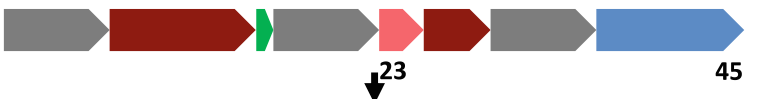

MQMEKKEWQAPALEVLEVNQTMAGTGYRQIDWITVHDADLYDPTS

i B. endophyticus FH5 (cluster 1) Lasso peptide BGC 5743bp

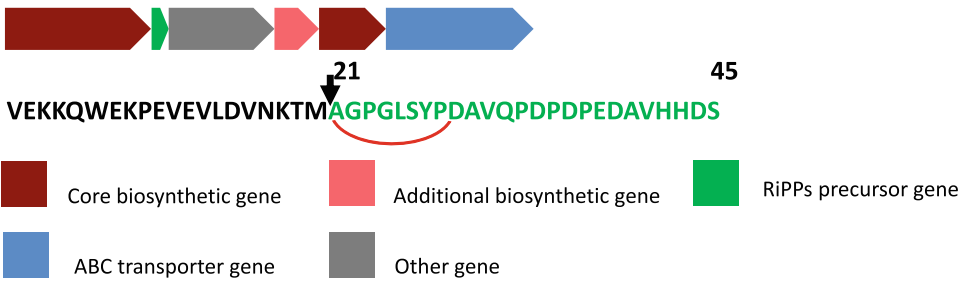

Fig. 5 (See legend on next page.) 
(See figure on previous page.)

Fig. 5 Novel bacteriocin Biosynthetic Gene Clusters (BGCs) identified from the isolated Bacillus and Paenibacillus strains. a, b two different class I lanthipeptide BGCs discovered in B. subtilis DH12 and Paenibacilus sp. EDO6 respectively. c class II lanthipeptide BGC found in both B. cabrialesii BH5 and BH6. d, e two different class II lanthipeptide BGCs discovered in B. subtilis EH5 and B. endophyticus FH5 respectively. $\mathbf{f}, \mathbf{g}$ two different class III lanthipeptide BGCs found in B.subtilis EH2, B. velezensis TH16 respectively. $\mathbf{h}$ two different lasso peptide BGCs discovered in Paenibacillus sp. EDO6 and B. endophyticus $\mathrm{FH} 5$ respectively

33.3\% identity to the paeninodin [44] from $P$. dendritiformis C454. Another novel lasso peptide BGC was mined from B. endophyticus FH5 (Fig. 5i). This BGC comprised of six genes. It is showing $80 \%$ genes similarity to paeninodin. Its precursor peptide contains 45 amino acids. The cleaveage site is between M20 and A21. The core peptide (from A21 to S45) has 76\% identity to the paeninodin.

\section{Large-scale genome-based analysis of the bioactive potential of Bacillus}

Lipopetides produced by the Bacillus genus are involved in the biocontrol mechanisms of plant pathogens [45]. To gain a general overview of BGCs distributed in the genomes of Bacillus genus, the diversity of BGCs in the genomes of Bacillus isolated was investigated. A total of 9459 BGCs were predicted and identified, which included NRPs (2377 BGCs), RiPPs (1564 BGCs), Type I PKs (517 BGCs), PKs-NRPs hybrids (309 BGCs), PKs (including Trans AT-PKs and Type III PKs) (1369 BGCs), Terpene (970 BGCs), Saccharide (62 BGCs) and Others (2291 BGCs).

The similarity network of predicted BGCs revealed that a large number of BGCs are present in Bacillus strains, and are distributed throughout different kinds of secondary metabolites (Fig. 6). Based on our investigation, some of the NRPs BGCs were conserved among the BGCs identified in the Bacillus species. 259 out of 2377 (10.85\%) NRPs BGCs were encoding surfactin, $330(13.88 \%)$ BGCs were encoding bacillibactin, 110 (4.63\%) NRPs BGCs were encoding fengycin, 158 (6.65\%) NRPs BGCs were encoding petrobactin [46]. And 38 (1.60\%) NRPs BGCs were encoding lichenysin [47]. Thus, a total of $38 \%$ of the NRPs BGCs are correlated to already reported compounds. Additionally, most of PKs-NRPs hybrid BGCs (67.64\%) were ecoding bacillaene. Unlike the well-described NRPs and PKs-NRPs hybrid BGCs, the PKs BGCs were mostly attributed to unknown products with the exception of macrolactin [48] and difficidin [29]. Notably, 1357 out of 1564 (87.76\%) RiPPs BGCs were also unknown. Overall, the distribution of known and unknown BGCs vary dramatically across the different kinds of metabolites in Bacillus species, in which the NRPs BGCs are the most abundant ones, comprising 2377 BGCs. Many of them are conserved and already characterized, but still a large number of unknown NRPs BGCs are identified for further study.

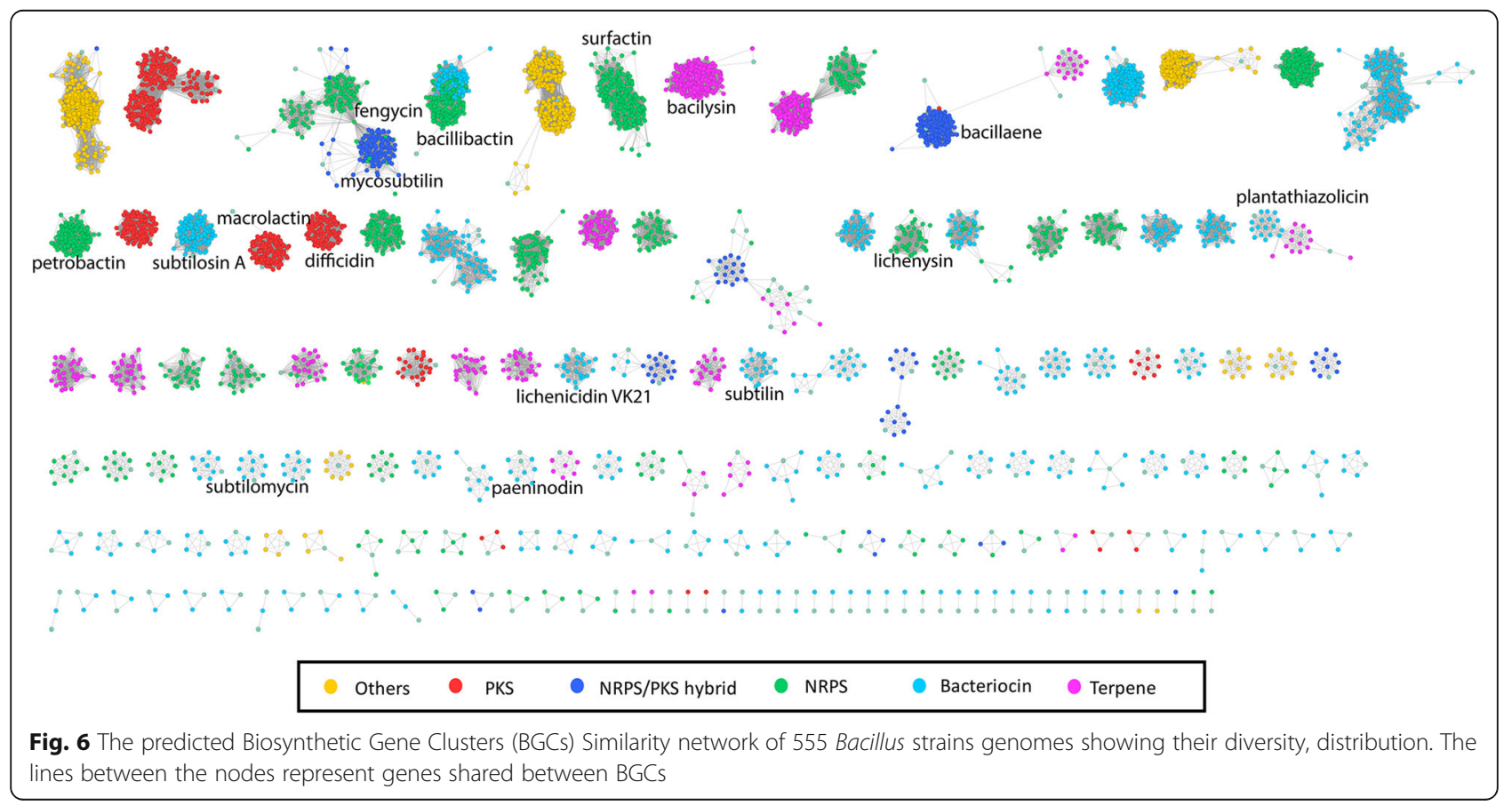




\section{Disscussion}

Bacillus strains attract more and more attention due to their ability to produce hard, resistant endospores and antibiotics which have the potential to be used as biocontrol agents. In this study, We found that 34 Bacillus strains (out of 181 Bacillus-like strains) have antagonistic activity against six major tomato plant pathogens $(E$. carotovora, P. syringae, $R$. solani, B. cinerea, V. dahliae, and $P$. infestans). These results suggest that these strains have potentials for tomato diseases control. 16S rRNA gene sequences comparison of 34 Bacillus strains highlighted the diversity of Bacillus strains exhibiting antagonistic activity against plant pathogens, suggesting that strains from rhizosphere soil encounter different plant pathogens, resulting in the acquisition of antagonistic activity during evolution. The 34 Bacillus strains were clustered into three large clades according to their $16 \mathrm{~S}$ rRNA sequences. By comparing the inhibition activity on the growth of each plant pathogen between these 34 strains, the most strongly inhibitory strains were closely related to $B$. subtilis and $B$. velezensis, suggesting that strains from $B$. subtilis and B. velezensis species possess strain-specific clusters of genes related to the biosynthesis of secondary metabolites, which play significant roles in pathogen suppression. In addition, among the 10 strains selected, two strains identified as B. cabrialesii $\mathrm{BH} 5$ and $\mathrm{BH} 6$ showed a growth reduction against all six major tomato plant pathogens (Fig. 1). This finding is the first record of this species that could exhibit antagonistic activity against tomato pathogens, which serves as a basis to further identify and characterize the interaction mechanisms between species B. cabrialesii and tomato pathogens.

Based on the genome mining, a total of 14 novel BGCs were revealed from the genomes of 10 sequenced strains. Five novel clusters were identified as NRPs and PKsNRPs hybrid BGCs. These categories of BGCs encode non-ribosomally synthesized peptides synthetases (NRPSs) and hybrid polyketides synthases and nonribosomally synthesized peptides synthetases (PKSNRPSs), which are modular multienzymes. NRPSs construct peptides from amino acids and PKS-NRPSs construct hybrid molecules from acyl-CoA moieties together with amino acids [49]. So far, some known bioactive compounds identified from Bacillus strains belong to these modular biosynthetic compounds, such as surfactin [24], iturin [50], bacillomycin [24], fengcin [24] and difficidin [29]. All of them are antimicrobials which can be used for biocontrol in agriculture. As the economic loss caused by plant diseases is increasing in recent years, it is worthwhile to investigate the compounds produced by the five novel modular BGCs identified. Due to the antagonistic assays in vitro, we speculate some of them have antibacterial and (or) antifungal activities. This needs to be characterized by experiments in the future. Especially, the novel NRPs BGC identified from $B$. velezensis $\mathrm{FH} 17$ and $\mathrm{TH} 16$ possess a single heterocyclization (Cy) domain in the first module, which could modify cystine (Cys) to form a thiazoline ring. This domain first catalyzes amide bond formation, and then the intramolecular cyclodehydration between the side chain of the first amino acid (Cys) and the backbone carbonyl carbon takes place to form a thiazoline ring [51]. This ring is important for the structure and function of this lipopeptide product. So far, many wellknown drugs for anti-microbial and anti-cancer activity exhibit thiazoline rings [52], such as Sulfathiazole (antimicrobial drug), Ritonavir (anti-retroviral drug), Tiazofurin (anti-neoplastic drug) and Abafungin (anti-fungal drug) [53]. These findings point to the potential antimicrobial activity of the compounds produced by this novel BGC in B. velezensis FH17 and TH16. Moreover, nine novel RiPPs BGCs were discovered. They are categorized into lanthipeptide I/II/III and lasso peptide BGCs. Lanthipeptides (also called lantibiotics for those with antibacterial activities) are ribosomally synthesized post-translationally modified peptides having thioether cross-linked amino acids, lanthionines, as a structural element [54]. They have potentials to be used as therapeutics. Subtilin, a lanthipeptide I, is one of the most studied bacteriocins from the Bacillus strains [15]. It is synthesized by spa BGC which is possessing strong antibiotic activities [55]. Mersacidin, is produced by $m r s$ BGC in Bacillus sp. HIL Y-85/54728 which is belonging to lanthipeptide II. It has activity against Gram-positive bacteria including Staphylococcus aureus, Streptococcus pneumoniae and Enterococcus faecium [55]. However, to date, only Lanthipeptide I and II have been reported from Bacillus strains. Here, we report two class III lanthipeptide BGCs from Bacillus strains (Fig. $5 \mathrm{f}$ and g). Unlike other class III lathipeptides, the one from $B$. velezensis TH16 only consists of one lanthionine/labionin moiety instead of two. Both in vivo and in vitro maturation of this peptides have value to be investigated in the future. With an increasing number of genomes, more and more lanthipeptides BGCs are certainly discovered, but only a few of them have been characterized by experimental researches. Lasso peptides contain a macrocyclic linkage between an Asp or Glu side chain to the $\mathrm{N}$ - terminus of the core peptide. The C-terminal tail is threaded through the macrocycle, giving a lariat topology for which the lasso peptides are named [56]. Until now, some lasso peptides are reported with antimicrobial activity. i.e. lariatin [57], lassomycin [58] and microcin J25 [59]. However, we can not predict the compounds produced by these nine novel lanthipeptides and lasso peptides BGCs are antimicrobials or not, which also need to be investigated by further experiments. These 14 
novel BGCs identified from Bacilllus stains appear to have different NRPs modules, precursor peptides or extra genes that might lead to modification on the biosynthetic pathway, changing the compound's structure and their activity. Therefore, these novel BGCs are of great interest for antimicrobial activity and novel drug discovery. The expression of BGCs into biological active compounds, providing the real biocontrol effect of Bacillus sp., is still the main challenge. So far, it remains difficult to predict the exact compound products from genome sequence data only. Exploring the biosynthetic capacity of Bacillus sp. by genome mining in combination with advanced mass spectrometry techiniques provide feasible solution for future compounds identification and characterization.

The result of large-scale genome mining of bioactive potential of Bacillus shows the distribution of known and unknown BGCs varying dramatically across the different kinds of metabolites in Bacillus species. NRPs and PKs-NRPs BGCs in Bacillus species are encoding highly conserved known compounds as well as various novel variants. These findings are consistent with KirK J. Grubbs [60] reported. They found that majority of Bacillus natural products are comprised of a small set of highly conserved, well-distributed, known natural product compounds. The genus Bacillus is well known for the natural products with antibacterial and antifungal activities, which has a strong potential to be applied to agriculture for plant diseases control [61]. Therefore, novel antimicrobials discovery is in need of identification and characterization of novel BGCs in Bacillus strains.

\section{Conclusions}

This work showed that 10 Bacillus and Paenibacillus strains, selected from 181 isolated Bacillus-like strains from the rhizosphere soil of healthy tomato plants and their tissues, have strong in vitro antagonistic activity against tomato bacterial, fungal and oomycetal pathogens. Based on genome mining, we identified a large number of BGCs from their genome sequences encoding known and unknown compounds, which form a great source for pharmaceutical compound discovery. Furthermore, a total of 14 novel BGCs were characterized in detail, including 2 NRPs, 3 PKs-NRPs hybrid and 9 RiPPs BGCs. In addition, from the large-scale bioinformatics analysis of the genomes from Bacillus genus, we found that NRPS and PKS-NRPS BGCs resources hidden in Bacillus species are frequently encoding highly conserved known compounds including surfactin, fengycin, bacillibactin, petrobactin, lichenysin and bacillaene.

\section{Methods}

\section{Sample collection, Bacteria isolation, and culture conditions}

Healthy tomato plants (cultivar: Boludo) and their rhizosphere soil were carefully collected during spring
(February 2017) from tomatoes grown in a garden in the village of Roden in the Netherlands and Almería in Spain, which were given to us by company Koppert and with their consent. The bacterial isolation was performed as described previously [22]. Briefly, $1 \mathrm{~g}$ rhizosphere soil was suspended in $9 \mathrm{ml}$ of $10 \mathrm{mM}$ sterilized $\mathrm{MgSO}_{4}$ buffer. Then the suspension was diluted $10^{3}-10^{6}$ times with $10 \mathrm{mM}$ sterilized $\mathrm{MgSO}_{4}$ buffer. After dilution, all the samples were heat-treated at $80^{\circ} \mathrm{C}$ for 15 min. and subsequently spread on Luria-Bertani (LB) agar plates. The plates were incubated at $28^{\circ} \mathrm{C}$ for $24-48 \mathrm{~h}$ to obtain single colonies. For the isolation of endophytes, 1 g tomato leaves were surface-sterilized for $1 \mathrm{~min}$. in $70 \%$ ethanol and $3 \mathrm{~min}$. in $0.5 \% \mathrm{NaClO}$ solution supplemented with one droplet Tween 80 per $100 \mathrm{ml}$ solution and then rinsed 5 times with sterilized deionized water. After surface sterilization, the leaves were macerated in $9 \mathrm{ml}$ of $10 \mathrm{mM}$ sterilized $\mathrm{MgSO}_{4}$ buffer with a sterilized mortar to obtain the suspension. The following steps were the same as isolation from rhizosphere soil. The surface-sterilization process was checked by spreading aliquots of the last rinsing deionized water on LB agar plates (if no organism growth was observed after 7 days, surface sterilization was considered to be successful). All the isolated strains were stored in $25 \%$ glycerol solution at $-80^{\circ} \mathrm{C}$ untill further investigation.

\section{Screening of antimicrobial activity}

In vitro antagonistic activity assays were performed on dual culture plates as described before with slight modification [62]. All the isolated strains were screened against different bacterial, fungal and oomycetal plant pathogens, such as E. carotovora, P. syringae, $R$. solani, B. cinerea, $V$. dahliae, and $P$. infestans. All the isolated strains were tested with different pathogens in triplicates.

To test antibacterial activity, bacterial pathogens were mixed with pre-cooled LB agar media (around $55^{\circ} \mathrm{C}$ ) at a final concentration of $1 \times 10^{6}$ cells $/ \mathrm{ml}$. Then the mixed media was poured into Petri dishes to obtain pathogenfusion agar plates. $5 \mathrm{ul}$ of $1 \times 10^{8}$ cells $/ \mathrm{ml}$ overnight culture of each isolated strain was inoculated at the center of plates. All the plates were incubated at $28^{\circ} \mathrm{C}$ for 2 days before the clear halo surrounding the strain isolated was measured.

Antagonistic activity of isolated strains against $R$. solani was tested as follows. A $0.5-\mathrm{cm}$ mycelium plug of 3 -day-old $R$. solani was placed at the center of the $1 / 5$ th PDA plate, and 5 ul of $1 \times 10^{8}$ cells $/ \mathrm{ml}$ overnight culture of each isolated strain was inoculated at a distance of 2 $\mathrm{cm}$ from the fungus. Plates were incubated at $28^{\circ} \mathrm{C}$ for 3 days and inhibition of fungal growth was recorded as the diameter of the inhibition zone $(\mathrm{mm})$. As a control, LB media was used in place of the bacterial suspension.

Antagonistic activity determination of isolated strains against $B$. cinerea, $V$. dahliae, and $P$. infestans was 
performed similarly as the antibacterial activity assay. Spores of $B$. cinerea and $V$. dahliae were collected respectively from 7-day-old and 20-day-old PDA plates with sterilized Mili-Q water by washing the mycelium. All the spores were counted using a Thoma chamber and were then mixed into $1 / 5$ th PDA media and adjusted to $1 \times 10^{7}$ spores $/ \mathrm{ml}$. In addition, sporangia of $P$. infestans were harvested by washing the 30-day-old RSA plates with sterilized mili-Q water and then counted and mixed into $1 / 5$ th PDA media at the final concentration of 4000 sporangia/ml. Before mixing, the sporangia suspension was stimulated to release zoospores by chilling for $1-3 \mathrm{~h}$ at $4{ }^{\circ} \mathrm{C}$. Subsequently, the mixed $1 / 5$ th PDA media was poured into Petri dishes. 5 ul of $1 \times 10^{8}$ cells $/ \mathrm{ml}$ overnight culture of each isolated strain was inoculated at the center of plates. All the plates were incubated at $28^{\circ} \mathrm{C}$. The clear halo surrounding each isolated strain was monitored and measured depending on the pathogens' growth rate.

\section{Identification of bacterial strains}

The isolated strains showing activity against pathogens were identified through partial 16S rRNA sequence homology analysis. The polymerase chain reaction (PCR) was carried out with bacterial-specific $16 \mathrm{~S}$ rRNA primers 27F (5'-AGAGTTTGATCMTGGCTCAG-3') and 1492R (5'-CGGTTACCTTGTTACGACTT-3') using genomic DNA as templates. The PCR $(50 \mu \mathrm{l})$ contained following final concentrations: $10 \mu \mathrm{l}$ of five-fold high fidelity Phusion buffer (Thermo Scientific), $0.4 \mathrm{mM}$ of each of the four deoxynucleoside triphosphates (Thermo Scientific), $0.4 \mu \mathrm{M}$ of each primer, $0.5 \mathrm{U}$ of Phusion high fidelity DNA polymerase (Thermo Scientific), and $~ 50$ $\mathrm{ng}$ of the isolated genomic DNA. The following thermal cycling scheme was used: initial denaturation at $98^{\circ} \mathrm{C}$ for $3 \mathrm{~min}, 30$ cycles of denaturation at $98^{\circ} \mathrm{C}$ for $15 \mathrm{~s}$, annealing at $56^{\circ} \mathrm{C}$ for $15 \mathrm{~s}$, extension at $72{ }^{\circ} \mathrm{C}$ for $50 \mathrm{~s}$, followed by an additional extension step at $72{ }^{\circ} \mathrm{C}$ for 7 min. The PCR products were then purified with a NucleoSpin Gel and PCR Clean-up kit (Macherey-Nagel) and sequenced at Macrogen Inc. The resulting $16 \mathrm{~S}$ rRNA gene sequences were compared in a BLAST search to the NCBI database. Phylogenetic analysis was performed using the MEGA software package (Version $\mathrm{X}$ [63]. The relationships between sequences were analyzed using the neighbor-joining method. Bootstrap analysis was used to evaluate the tree topology of the neighbor-joining data by analyzing 1000 randomized data sets. The phylogenetic tree was visualized in iTOL version 4.4.2 [64].

\section{Genome sequencing and phylogenetic analysis}

Genomic DNA of isolates was extracted with a GenElute Bacterial Genomic DNA kit (Sigma) according to the manufacturer's protocol and sequenced at GATC Biotech (Germany) with an Illumina HiSeq sequencing system. The draft genomes were assembled and deposited in GeneBank. For the classification of species affiliations, $\mathrm{dDDH}$ and ANI values were calculated using the web tools TYGS [65] and JSpeciesWS [66] respectively. Two genomes belonging to the same species would have a $\mathrm{dDDH}$ of at least $70 \%$, which corresponds to at least 95\% ANI [23]. The whole genomes were then compared with other reference genomes using the GEGENEES tool [67] based on a fragmented nucleotides alignment with a setting of 200/100. A phylogenetic tree was generated with iTOL version 4.4.2 [64] and Splitstree [68].

\section{Antimicrobial compounds mining among 10 isolated strains}

For identification of biosynthesis gene clusters (BGCs) in isolated strains, each draft genome was assembled into a pseudomolecule using Medusa web server (http:// combo.dbe.unifi.it/medusa) [69] based on multiple closely related strains as references. And then all the pseudomolecules were send to antiSMASH [70] and BAGEL4 [71] for BGCs mining.

\section{Metabolite BGC network analysis among Bacillus strains} The complete genomes of 555 Bacillus strains from 60 species of Bacillales were downloaded from Genebank and analyzed by antiSMASH 5.0 [70]. The similarity network between BGCs was calculated with BiG-SCAPE (https://git.wageningenur.nl/medema-group/BiG-

SCAPE) [72]. A program that constructs sequence similarity networks of BGCs and groups them into Gene Cluster Families (GCFs) [72]. To visualize, the distance matrix between BGCs generated by BiG-SCAPE was exported and annotated in Cytoscape v3.7.0 (http:// www.cytoscape.org/) [73]. Default parameters were used for all software unless noted.

\section{Supplementary Information}

The online version contains supplementary material available at https://doi. org/10.1186/s12864-020-07346-8.

Additional file 1: Table S1. Digital DNA-DNA Hybridization (dDDH)

values (in upper triangle) and Average Nucleotide Identity (ANI) values (in lower triangle) amongst different strains. Table S2. All BGCs (including

known and unknown) found in each genome of selected strains.

\section{Abbreviations}

PGPR: Plant growth promoting rhizobacteria; BGCs: Biosynthetic gene clusters; ISR: Inducing systemic resistance; NRPSs: Non-ribosomally synthesized peptides synthetases; PKSs: Polyketides synthases; NRPs: Nonribosomally synthesized peptides; PKs: Polyketides; PKS-NRPSs: Hybrid polyetides synthases and non-ribosomally synthesized peptides synthetases; RiPPs: Ribosomally synthesized and post-translationally modified peptides; PTMs: Posttranslational modifications; C: Condensation; A: Adenylation; T: Thiolation; E: Epimerization; TE: Thioesterase; KS: Ketosynthase; 
AT: Acyltransferase; ACP: Acyl carrier protein; TD: Reductase;

DHt: Dehydratase domain variant; Cy: Heterocyclization

\section{Acknowledgements}

We thank the Koppert company in Netherlands for providing tomato plants and their rhizosphere soil and Dr. Sjoerd van der Meulen for garden samples.

\section{Authors' contributions}

LZ and OPK conceived the study and designed experiments. LZ and CS conducted the experiments. LZ performed the bioinformatic analysis and wrote the draft manuscript. $L Z, C S, Z L$ and OPK corrected the manuscript. All authors have read and approved the manuscript

\section{Funding}

L. Zhou was financially supported by the China Scholarship Council (201606910037). C. Song was supported by a grant of NWO-STW for the Back to the Roots project. Z. Li was financially supported by the China Scholarship Council. The funders had no role in study design, data collection and analysis, decision to publish, or preparation of manuscript.

\section{Availability of data and materials}

The whole genome data are available at DDBJ/EMBL/GenBank under the bioproject accession PRJNA503984 (https://www.ncbi.nlm.nih.gov/bioproject/ PRJNA503984/).

\section{Ethics approval and consent to participate}

Not applicable.

\section{Consent for publication}

Not applicable.

\section{Competing interests}

The authors declare that they have no conflict interests.

\section{Author details}

'Department of Molecular Genetics, University of Groningen, Groningen, The Netherlands. ${ }^{2}$ National Academy of Agriculture Green Development, Key Laboratory of Plant-Soil Interactions, Ministry of Education, College of Resources and Environmental Sciences, China Agricultural University, Beijing 100193, China.

Received: 4 May 2020 Accepted: 22 December 2020

Published online: 07 January 2021

\section{References}

1. Olaniyi J, Akanbi W, Adejumo T, Ak OJ. Growth, fruit yield and nutritional quality of tomato varieties. Afr J Food Sci. 2010:4:398-402.

2. Dias MP, Bastos MS, Xavier VB, Cassel E, Astarita LV, Santarem ER. Plant growth and resistance promoted by Streptomyces spp. in tomato. Plant Physiol Biochem. 2017;118:479-93.

3. Asaka O, Shoda MJAEM. Biocontrol of Rhizoctonia solani damping-off of tomato with Bacillus subtilis RB14. Appl Environ Microbiol. 1996;62:4081-5.

4. Barea JM, Pozo MJ, Azcon R, Azcon-Aguilar C. Microbial co-operation in the rhizosphere. J Exp Bot. 2005;56:1761-78.

5. Raaijmakers JM, Paulitz TC, Steinberg C, Alabouvette C, Moënne-Loccoz Y. The rhizosphere: a playground and battlefield for soilborne pathogens and beneficial microorganisms. Plant Soil. 2009;321:341-61.

6. Philippot L, Raaijmakers JM, Lemanceau P, van der Putten WH. Going back to the roots: the microbial ecology of the rhizosphere. Nat Rev Microbiol. 2013;11:789-99.

7. Lynch J, Whipps JJP. Substrate flow in the rhizosphere. Plant Soil. 1990;129. $1-10$.

8. Whipps JM. Microbial interactions and biocontrol in the rhizosphere. J Exper Botany. 2001;52:487-511

9. Silo-Suh LA, Lethbridge BJ, Raffel SJ, He H, Clardy J, Handelsman J. Biological activities of two fungistatic antibiotics produced by Bacillus cereus UW85. Appl Environ Microbiol. 1994;60:2023-30.

10. Wang S, Wu H, Qiao J, Ma L, Liu J, Xia Y, Gao X. Molecular mechanism of plant growth promotion and induced systemic resistance to tobacco mosaic virus by Bacillus spp. J Microbiol Biotechnol. 2009;19:1250-8.
11. Ryu C-M, Farag MA, Hu C-H, Reddy MS, Kloepper JW, Paré PW. Bacterial volatiles induce systemic resistance in Arabidopsis. Plant Physiol. 2004;134 1017-26.

12. Choudhary DK, Johri BN. Interactions of Bacillus spp. and plants--with special reference to induced systemic resistance (ISR). Microbiol Res. 2009; 164:493-513.

13. Ongena M, Duby F, Jourdan $E$, Beaudry $T$, Jadin $V$, Dommes J, Thonart $P$. Bacillus subtilis M4 decreases plant susceptibility towards fungal pathogens by increasing host resistance associated with differential gene expression. Appl Microbiol Biotechnol. 2005;67:692-8.

14. Perez-Garcia A, Romero D, de Vicente A. Plant protection and growth stimulation by microorganisms: biotechnological applications of bacilli in agriculture. Curr Opin Biotechnol. 2011;22:187-93.

15. Caulier S, Nannan C, Gillis A, Licciardi F, Bragard C, Mahillon J. Overview of the antimicrobial compounds produced by members of the Bacillus subtilis group. Front Microbiol. 2019;10:302

16. Crits-Christoph A, Diamond S, Butterfield CN, Thomas BC, Banfield JF. Novel soil bacteria possess diverse genes for secondary metabolite biosynthesis. Nature. 2018:558:440-4.

17. Alippi A, Bó ED, Ronco L, Casanova P, Aguilar O. Tomato as a new host of Erwinia carotovora subsp. carotovora in Argentina. Plant Dis. 1997:81:230.

18. Buell CR, Joardar V, Lindeberg M, Selengut J, Paulsen IT, Gwinn ML, Dodson RJ, Deboy RT, Durkin AS, Kolonay JF. The complete genome sequence of the Arabidopsis and tomato pathogen Pseudomonas syringae pv. tomato DC3000. Proc Natl Acad Sci. 2003;100:10181-6.

19. El Oirdi M, Abd El Rahman T, Rigano L, El Hadrami A, Rodriguez MC, Daayf F, Vojnov A, Bouarab K. Botrytis cinerea manipulates the antagonistic effects between immune pathways to promote disease development in tomato. Plant Cell. 2011;23:2405-21.

20. Bhat $R$, Subbarao K. Host range specificity in Verticillium dahliae. Phytopathology. 1999;89:1218-25

21. Legard D, Lee T, Fry W. Pathogenic specialization in Phytophthora infestans: aggressiveness on tomato. Phytopathology. 1995;85:1356-61.

22. Zhou L, Song C, de Jong A, Kuipers OP. Draft Genome Sequences of 10 Paenibacillus and Bacillus sp. Strains Isolated from Healthy Tomato Plants and Rhizosphere Soil. Microbiol Resour Announc. 2019:8:e00055-19.

23. Orata FD, Meier-Kolthoff JP, Sauvageau D, Stein LY. Phylogenomic analysis of the Gammaproteobacterial Methanotrophs (order Methylococcales) calls for the reclassification of members at the genus and species levels. Front Microbiol. 2018;9:3162

24. Koumoutsi A, Chen XH, Henne A, Liesegang H, Hitzeroth G, Franke P, Vater $J$, Borriss R. Structural and functional characterization of gene clusters directing nonribosomal synthesis of bioactive cyclic Lipopeptides in Bacillus amyloliquefaciens strain FZB42. J Bacteriol. 2004;186:1084-96.

25. Chen XH, Koumoutsi A, Scholz R, Borriss R. More than anticipated production of antibiotics and other secondary metabolites by Bacillus amyloliquefaciens FZB42. J Mol Microbiol Biotechnol. 2009:16:14-24.

26. Kawulka KE, Sprules T, Diaper CM, Whittal RM, McKay RT, Mercier P, Zuber P, Vederas JCJB. Structure of subtilosin a, a cyclic antimicrobial peptide from Bacillus subtilis with unusual sulfur to a-carbon cross-links: formation and reduction of a-thio-a-amino acid derivatives. Biochemistry. 2004:43:3385-95.

27. Moldenhauer J, Chen $\mathrm{XH}$, Borriss R, Piel J. Biosynthesis of the antibiotic bacillaene, the product of a giant polyketide synthase complex of the transAT family. Angew Chem Int Ed Engl. 2007:46:8195-7.

28. Schneider $K$, Chen X-H, Vater J, Franke P, Nicholson G, Borriss R, Süssmuth $\mathrm{RD}$. Macrolactin is the Polyketide Biosynthesis Product of the pks2 Cluster of Bacillus amyloliquefaciens FZB42. J Nat Prod. 2007;70(9):1417-23.

29. Chen XH, Vater J, Piel J, Franke P, Scholz R, Schneider K, Koumoutsi A, Hitzeroth G, Grammel N, Strittmatter AW, et al. Structural and functional characterization of three polyketide synthase gene clusters in Bacillus amyloliquefaciens FZB 42. J Bacteriol. 2006;188:4024-36.

30. Klein C, Kaletta C, Entian K. Biosynthesis of the lantibiotic subtilin is regulated by a histidine kinase/response regulator system. Appl Environ Microbiol. 1993;59:296-303

31. Kautsar SA, Blin K, Shaw S, Navarro-Muñoz JC, Terlouw BR, van der Hooft JJ, Van Santen JA, Tracanna V, Suarez Duran HG, Pascal Andreu V. MIBiG 2.0: a repository for biosynthetic gene clusters of known function. Nucleic Acids Res. 2020;48:D454-8.

32. Garcia-Gonzalez E, Muller S, Hertlein G, Heid N, Sussmuth RD, Genersch E Biological effects of paenilamicin, a secondary metabolite antibiotic 
produced by the honey bee pathogenic bacterium Paenibacillus larvae. Microbiologyopen. 2014;3:642-56.

33. Fiers WD, Dodge GJ, Sherman DH, Smith JL, Aldrich CC. Vinylogous dehydration by a Polyketide Dehydratase domain in Curacin biosynthesis. J Am Chem Soc. 2016;138:16024-36.

34. Jahns C, Hoffmann T, Muller S, Gerth K, Washausen P, Hofle G, Reichenbach $H$, Kalesse M, Muller R. Pellasoren: structure elucidation, biosynthesis, and total synthesis of a cytotoxic secondary metabolite from Sorangium cellulosum. Angew Chem Int Ed Engl. 2012;51:5239-43.

35. Reimer D, Luxenburger E, Brachmann AO, Bode HB. A new type of pyrrolidine biosynthesis is involved in the late steps of xenocoumacin production in Xenorhabdus nematophila. Chembiochem. 2009;10:19972001.

36. Zhao X, Kuipers OP. Identification and classification of known and putative antimicrobial compounds produced by a wide variety of Bacillales species. BMC Genomics. 2016;17:882.

37. Xin B, Zheng J, Liu H, Li J, Ruan L, Peng D, Sajid M, Sun M. Thusin, a novel two-component Lantibiotic with potent antimicrobial activity against several gram-positive pathogens. Front Microbiol. 2016;7:1115.

38. Navaratna MA, Sahl H-G, Tagg JR. Identification of genes encoding twocomponent lantibiotic production in Staphylococcus aureus C55 and other phage group II S. aureus strains and demonstration of an association with the exfoliative toxin B gene. Infect Immun. 1999;67:4268-71.

39. Ryan MP, Jack RW, Josten M, Sahl H-G, Jung G, Ross RP, Hill C. Extensive post-translational modification, including serine to D-alanine conversion, in the two-component lantibiotic, lacticin 3147. J Biol Chem. 1999;274:3754450.

40. Holo H, Jeknic Z, Daeschel M, Stevanovic S, Nes IF. Plantaricin W from lactobacillus plantarum belongs to a new family of two-peptide lantibiotics. Microbiology. 2001;147:643-51.

41. Lawton EM, Cotter PD, Hill C, Ross RP. Identification of a novel two-peptide lantibiotic, haloduracin, produced by the alkaliphile Bacillus halodurans C125. FEMS Microbiol Lett. 2007;267:64-71.

42. Zhang $\mathrm{Q}, \mathrm{Yu}$ Y, Velasquez JE, van der Donk WA. Evolution of lanthipeptide synthetases. Proc Natl Acad Sci U S A. 2012;109:18361-6.

43. Luo C, Liu X, Zhou H, Wang X, Chen Z. Nonribosomal peptide synthase gene clusters for lipopeptide biosynthesis in Bacillus subtilis 916 and their phenotypic functions. Appl Environ Microbiol. 2015;81:422-31.

44. Zhu S, Hegemann JD, Fage CD, Zimmermann M, Xie X, Linne U, Marahiel MA. Insights into the unique phosphorylation of the lasso peptide Paeninodin. J Biol Chem. 2016;291:13662-78.

45. Ongena M, Jacques P. Bacillus lipopeptides: versatile weapons for plant disease biocontrol. Trends Microbiol. 2008;16:115-25.

46. Cendrowski S, MacArthur W, Hanna P. Bacillus anthracis requires siderophore biosynthesis for growth in macrophages and mouse virulence. Mol Microbiol. 2004;51:407-17.

47. Veith B, Herzberg C, Steckel S, Feesche J, Maurer KH, Ehrenreich P, Bäumer S, Henne A, Liesegang H, Merkl R. The complete genome sequence of Bacillus licheniformis DSM13, an organism with great industrial potential. J Mol Microbiol Biotechnol. 2004;7:204-11.

48. Schneider $\mathrm{K}$, Chen X-H, Vater J, Franke P, Nicholson G, Borriss R, Süssmuth $\mathrm{RD}$. Macrolactin is the polyketide biosynthesis product of the pks 2 cluster of Bacillus amyloliquefaciens FZB42. J Nat Prod. 2007;70:1417-23.

49. Weissman KJ. The structural biology of biosynthetic megaenzymes. Nat Chem Biol. 2015:11:660-70.

50. Tsuge K, Akiyama T, Shoda M. Cloning, sequencing, and characterization of the iturin a operon. J Bacteriol. 2001;183:6265-73.

51. Bloudoff K, Fage CD, Marahiel MA, Schmeing TM. Structural and mutational analysis of the nonribosomal peptide synthetase heterocyclization domain provides insight into catalysis. Proc Natl Acad Sci U S A. 2017;114:95-100.

52. Kumawat MK. Thiazole containing heterocycles with antimalarial activity. Curr Drug Discov Technol. 2018;15:196-200

53. Rouf A, Tanyeli C. Bioactive thiazole and benzothiazole derivatives. Eur J Med Chem. 2015;97:911-27.

54. Ongey EL, Neubauer P. Lanthipeptides: chemical synthesis versus in vivo biosynthesis as tools for pharmaceutical production. Microb Cell Factories. 2016;15:97.

55. Barbosa J, Caetano T, Mendo S. Class I and class II Lanthipeptides produced by Bacillus spp. J Nat Prod. 2015;78:2850-66.

56. Tietz Jl, Schwalen CJ, Patel PS, Maxson T, Blair PM, Tai HC, Zakai UI, Mitchell DA. A new genome-mining tool redefines the lasso peptide biosynthetic landscape. Nat Chem Biol. 2017;13:470-8.
57. Inokoshi J, Matsuhama M, Miyake M, Ikeda H, Tomoda H. Molecular cloning of the gene cluster for lariatin biosynthesis of Rhodococcus jostii K01-B0171. Appl Microbiol Biotechnol. 2012;95:451-60.

58. Gavrish E, Sit CS, Cao S, Kandror O, Spoering A, Peoples A, Ling L, Fetterman A, Hughes D, Bissell A, et al. Lassomycin, a ribosomally synthesized cyclic peptide, kills mycobacterium tuberculosis by targeting the ATP-dependent protease ClpC1P1P2. Chem Biol. 2014;21:509-18.

59. Wilson K-A, Kalkum M, Ottesen J, Yuzenkova J, Chait BT, Landick R, Muir T, Severinov K, Darst SA. Structure of microcin J25, a peptide inhibitor of bacterial RNA polymerase, is a lassoed tail. J Am Chem Soc. 2003;125: 12475-83.

60. Grubbs KJ, Bleich RM, Santa Maria KC, Allen SE, Farag S, AgBiome T, Shank EA, Bowers AA. Large-Scale Bioinformatics Analysis of Bacillus Genomes Uncovers Conserved Roles of Natural Products in Bacterial Physiology. mSystems. 2017;2:e00040-17.

61. Mohamad OAA, Li L, Ma JB, Hatab S, Xu L, Guo JW, Rasulov BA, Liu YH, Hedlund BP, Li WJ. Evaluation of the antimicrobial activity of Endophytic bacterial populations from Chinese traditional medicinal plant licorice and characterization of the bioactive secondary metabolites produced by Bacillus atrophaeus against Verticillium dahliae. Front Microbiol. 2018;9:924.

62. Chen Y, Yan F, Chai Y, Liu H, Kolter R, Losick R, Guo JH. Biocontrol of tomato wilt disease by Bacillus subtilis isolates from natural environments depends on conserved genes mediating biofilm formation. Environ Microbiol. 2013; 15:848-64.

63. Kumar S, Stecher G, Li M, Knyaz C, Tamura K. MEGA X: molecular evolutionary genetics analysis across computing platforms. Mol Biol Evol. 2018;35:1547-9.

64. Letunic I, Bork P. Interactive tree of life (iTOL) v4: recent updates and new developments. Nucleic Acids Res. 2019;47:W256-9.

65. Meier-Kolthoff JP, Goker M. TYGS is an automated high-throughput platform for state-of-the-art genome-based taxonomy. Nat Commun. 2019;10:2182.

66. Richter M, Rossello-Mora R, Oliver Glockner F, Peplies J. JSpeciesWS: a web server for prokaryotic species circumscription based on pairwise genome comparison. Bioinformatics. 2016;32:929-31.

67. Agren J, Sundstrom A, Hafstrom T, Segerman B. Gegenees: fragmented alignment of multiple genomes for determining phylogenomic distances and genetic signatures unique for specified target groups. PLoS One. 2012; 7:e39107.

68. Huson DH, Bryant D. Application of phylogenetic networks in evolutionary studies. Mol Biol Evol. 2006;23:254-67.

69. Bosi E, Donati B, Galardini M, Brunetti S, Sagot M-F, Lió P, Crescenzi P, Fani R, Fondi M. MeDuSa: a multi-draft based scaffolder. Bioinformatics. 2015;31: 2443-51.

70. Blin K, Shaw S, Steinke K, Villebro R, Ziemert N, Lee SY, Medema MH, Weber T. antiSMASH 5.0: updates to the secondary metabolite genome mining pipeline. Nucleic Acids Res. 2019;47:W81-7.

71. van Heel AJ, de Jong A, Song C, Viel JH, Kok J, Kuipers OP. BAGEL4: a userfriendly web server to thoroughly mine RiPPs and bacteriocins. Nucleic Acids Res. 2018;46:W278-81.

72. Yeong M. BiG-SCAPE: exploring biosynthetic diversity through gene cluster similarity networks; 2016

73. Saito R, Smoot ME, Ono K, Ruscheinski J, Wang P-L, Lotia S, Pico AR, Bader GD, Ideker T. A travel guide to Cytoscape plugins. Nat Methods. 2012;9:1069.

\section{Publisher's Note}

Springer Nature remains neutral with regard to jurisdictional claims in published maps and institutional affiliations.

\section{Ready to submit your research? Choose BMC and benefit from:}

- fast, convenient online submission

- thorough peer review by experienced researchers in your field

- rapid publication on acceptance

- support for research data, including large and complex data types

- gold Open Access which fosters wider collaboration and increased citations

- maximum visibility for your research: over $100 \mathrm{M}$ website views per year

At $\mathrm{BMC}$, research is always in progress.

Learn more biomedcentral.com/submissions 